P. I50, line 2. For $I \epsilon^{2} \cos ^{2} \omega$ in the denominator of the last term of the value of $\frac{d m}{n}$, read $I-\epsilon^{2} \cos ^{2} \omega$.

P. 214. Fig. 44, the letter $P$ out of place; compare with Germain's Fig. 98; in the letterpress "angle $A P C=\omega "$ should be $=\pi$.

Also the numbering of the sections seems to require some revision. Section VII. referred to in p. xiii. of the introduction, as containing Mr. Schott's account of the polyconic projection, is not of course the Section VII. of the text, and though Part II. is not divided into sections, yet in p. 230 "The Tables" appear under $\$$ xii.

\section{PROMISE AND PERFORMANCE IN CHINESE SCIENCE}

U NDER the title of "Science à la Chinoise," a writer in a recent number of the excellent North China Herald dwells on what may be called the disparity between the promise and the performance of Chinese science. The ancient classics contain beautiful maxims on the necessity for research into nature. The "Great Learning" tells us that knowledge is perfected by the investigation of nature; Confucius urged his pupils to study the "Book of Poetry," because, among other things, they could become acquainted with the names of plants and animals; Mencius tells us that the careful study of phenomena is the road to knowledge, and in illustration says: "Though heaven is high and the stars distant, yet, having investigated their phenomena, we can sit down and calculate their revolutions for a thousand years." It has long been a proverb among the learned that to be ignorant of a single thing is a disgrace to the true scholar, and to be ignorant of nature is as if nature did not exist. When the revered ancient sages of China, whose words are in the mouths of all, thus encourage scientific research, we should be led to anticipate great results from the patience, intelligence, and ingenuity of the Chinese. But, as in so many other respects in that anomalous country, we have excellent maxims and little more. There is, says this writer, neither research nor knowledge; science has no existence. There is indeed a considerable natural literature. From ancient times the Chinese have taken note of natural phenomena. Their record of solar eclipses is perhaps the most ancient and accurate in the world. They have more or less elaborate works on astronomy, mathematics, botany, zoology, mineralogy, physiology, and many other sciences. Yet there is scarcely any true science in them. Classification, even in regard to plants and animals, there is none. Mineralogy is mainly a description of curious stones. Nor is there any progress, for the more ancient wotks are generally the best, and as a consequence the Chinese to-day are as their fathers were thousands of years ago. The superstitions respecting natural phenomena, which are as living active truths to-day for all classes in China, remind us rather of man in his state of barbarism than of the ancient culture and civilisation of the Middle Kingdom. The sun and moon are to the Chinese as they were to primitive man, living things, god; to be worshipped. The stars in their courses powerfully influence, if they do not absolutely determinc all human events. In them the wise may read as in a book the destiny of man and the fate of empires. Their combinations make lucky and unlucky days, and we shall do well to note carefully their signs and silent warnings. Comcts are the precursors of famine, pestilen se, and war--prognosticators of the wreck of empires and the fall of kings. Eclipses are the periodic cfforts of the dragon fiend to destroy the lights of heaven, and every notice of an approaching eclipse sent by the Imperial astronomer to the provinces is accompanied by a Government order to employ the usual methods of gong-beating and so forth in order to rescue the threatened luminary. Again, thunder is the roar of the anger of heaven, and to be smitten by a thunderbolt is to be marked as a thing accursed. Wind is born in the heart of great mountains, whence it issues at the command of the wind-god. Most districts have their wind-mountains. That at Lung-Shan in the northern province of Chihli is the most remarkable. It has a cave at each of its four sides. The spring wind issues from the cave on the eastern side, the summer wind from the southern, and so for the others. Wind eddies or whirlwinds are raised by the hedgehog in his rapid passage from one place to another, the dust serving to screen him from the vulgar gaze. Rain is produced by the dragon god, who carries up vast quantities of water from the lakes and rivers in his capacious jaws, and pours it down in showers over the earth. Every mountain has its spirit or genius, every valley its nymph, every spring its naiad. Hence mountains and rivers, old trees and curious rocks, become objects of worship.

These and the like superstitions which enter every domain of nature are not confined to the poor and illiterate; they are shared by the rich and learned, nay, they are repeated and acknowledged by the Imperial Government itself in its decrees in the Peking Gazette. The highest scholar in the empire knows no more of nature than the humblest peasant. The years have come and gone, repeating the same old story, but there has been no ear to hear it, no mind to understand it. Nature has found no interpreter among the Chinese; during their long national life they have contributed nothing to science. How are we to account for this? In other fields of national effort, and especially as inventors, they must be allowed a high place. It cannot be indifference, for they have written largely on the beauties, marvels, and mystcries of nature, and many have shown keen interest in the discoveries of science. It may partly, perhaps, be due to the fact that the intellect of the nation is employed in the struggie for place and power along grooves in which sience has no part. The writer we quote thinks it is mainly owing to the narrow and perverted system of education; and while the present system continues the study of science will be impossible to the youth of China, The cleverest young men find it as much as they can do to take their first degree at twenty. The higher degrees, which are also the avenues to office, can scarcely be won for years later, and thus they cannot afford a thought for anything beyond the common curriculum.

\section{ON THE PROPERTIES OF WATER AND ICE ${ }^{1}$}

$D$ R. PETTERSON'S memoir is a most valuable contribution to our knowledge of the natural history of the waters of the globe. Every reader of Arctic voyages must be familiar with the variety of names attached to the different kinds of ice met with in these regions, such as "pack-ice," "bay-ice," "brash-ice," and the like. To one who has never secn them, the names convey very little information either of thcir appearance or of their mode of formation. Dr. Petterson's paper explains in a satisfactory and very remarkable manner the nature of the difference between the different kinds of ice.

In the first part of the work the subject is treated physically, and in the second chemically. In both parts there is much that is new and valuable.

In the Arctic Ocean, and especially in that part of it visited by the $V e g a$, the saltness of the water varies much from place to place. The large rivers of Siberia constantly pour forth fresh water which lies on the surface of the ocean and spreads round the coast like a fringe. This layer often extends a considerable distance out to sea, wherc it gradually thins out. Nearer the shore it is thicker, but wherever the depth exceeds 20 or 30 metres the dense ocean water is found below and the two layers I "On the Properties of Water and Ice." By Otto Petterson. Publication of the Vega Expedition. (Stockholn, $188_{3}$.) 